\title{
Limits and Potentialities of Studying Dryland Vegetation Using the Optical Remote Sensing
}

\author{
Mona Dawelbait ${ }^{1,2^{*}}$ and Francesco Morari ${ }^{2}$ \\ ${ }^{1}$ Department of Environmental Affairs, Ministry of Environment and Physical Development, Khartoum - Sudan \\ ${ }^{2}$ Dipartimento di Agronomia Ambientale e Produzioni Vegetali, Agripolis, Università di Padova \\ Viale dell'Università 16, 35020 Legnaro (PD), Italy
}

Received: 27 February 2008. Accepted: 10 August 2008.

\begin{abstract}
In optical remote sensing studies, the reflectance of the vegetation canopy in arid and semiarid areas is affected by the optical properties of the vegetation elements, their arrangement in the vegetation canopy and the optical properties of the surrounding environment. The study of vegetation and surrounding environment parameters presents significant peculiarities in arid areas. Low vegetation cover leads to a small contribution of vegetation reflectance in the total pixel reflectance relative to the other materials. Most types of dry ecosystem shrubs do not differ enough from one another to allow discernment of vegetation type. Vegetation in arid and semiarid areas adapts its structure and phenology to the harsh environment, which affects the overall brightness and temporal and spatial interspecies spectral variability. Moreover, the surrounding environment in dry ecosystem influences the reflectance of the vegetation by multiple scattering and nonlinear mixing and variable spectral composition of soil surface.

Many remote sensing techniques are insensitive to nonphotosynthetic vegetation, which can be a major component of total cover in dry ecosystem areas. Spectral mixture analysis (SMA) appears to be the most promising technique to obtain information on vegetation cover, soil surface type and vegetation canopy characteristics. The empirical signature libraries of the world's dominant vegetation types could be upgraded for use with SMA.
\end{abstract}

Key-words: desertification, remote sensing, vegetation, dryland, spectral mixture analysis.

\section{Introduction}

The concept of desertification dates back to colonial West Africa in the 1920s and 1930s, and was revived in the early 1970s in an attempt to understand the effects of a long series of drought years that brought environmental degradation, economic difficulty and hunger to the African Sahel (Lonergan, 2005). Many studies and assessments of dryland ecosystems since the United Nations Conference on Desertification (UNCOD) in 1977 have led to a valuable new understanding of the desertification issue. These studies pointed out significant shortcomings in terms of data and methodologies. Moreover, they call for the improvement of science and technology for environmental monitoring, assessment models, accurate databases and integrated information systems (Lonergan, 2005).

Remote sensing is a technology that can be used to measure and monitor important biophysical and biochemical characteristics of objects, as well as human activities on the Earth (Jensen, 2000). The meaning and value of remote sensing data is enhanced through skilled interpretation used in conjunction with conventionally mapped information and ground-collected data (Jensen, 2000). Remote sensing has long been suggested as a time and cost efficient method for observing dryland ecosystem environments (Hassan and Luscombe, 1990).

Optical remote sensing $(0.3-15 \mu \mathrm{m})$, both spaceborne and airborne, provides valuable tools for evaluating areas subject to desertification. It is used in many applications such as: 1) mapping and monitoring land use and land cover change and degradation, sand dunes, studying organic carbon in the surface soil layer, deriving information about chemical components

\footnotetext{
* Corresponding Author: Tel.: +39 049 8272857; Fax: +39 049 8272839. E-mail address: mona.dawelbait@unipd.it
} 
and mapping areas affected by high salt concentration; 2) studying dryland geomorphology; 3) evaluating the vegetation conditions (e.g. vigour, photosynthetic capacity or stress of vegetation canopy or cluster); 4) studying the atmospheric conditions by detecting mineral aerosols - dust suspended in the air - and water vapour in the atmosphere; 5) detecting the extent of desert (Okin and Robert, 2004).

Earth observation data, particularly Landsat Thematic Mapper (TM) and Multispectral Scanner (MSS) imagery, have been widely used in semiarid environments to show up variations in vegetation community characteristics from changes in their reflectance characteristics. Earth observation data are also used to estimate vegetation abundance depending on simple relationships between reduced reflectance and increased total plant cover or between a spectral vegetation index and green vegetation cover (Pickup, 1995). However, new problems are arising from the changes in vegetation community structure observed in the desert environment, notably due to a gradual increase in bush dominance and changes in the mix of palatable and unpalatable grasses (Trodd and Dougill, 1998).

This article introduces the reader to the problems of optical remote sensing in studying vegetation in dryland and focuses on: (1) studying the reflectance of vegetation and the surrounding environment in a dryland ecosystem; (2) discussing the techniques used to monitor and obtain information on the canopy in a dryland ecosystem.

\section{Reflectance of vegetation and surrounding environment in a dryland ecosystem}

In the wavelength range between 400 and 2500 $\mathrm{nm}$, the radiance reflected from a vegetation canopy is influenced by three main factors related to the canopy: (1) the optical properties of the vegetation elements, (2) the arrangement of these elements in the vegetation canopy and (3) the optical properties of the environment around the canopy (soil and atmosphere) (Dorigo et al., 2007).

The difficulties facing evaluation of vegetation using optical remote sensing in a dryland ecosystem arise from different types of problems.

\subsection{Anomalies in the optical properties of the vegetation elements}

Vegetation in a dryland ecosystem suffers from water scarcity due to low precipitation and high potential evapotranspiration, so vegetation cover is low. This leads to the small contribution of vegetation reflectance in the total pixel reflectance relative to the other materials in a dryland ecosystem. Therefore, the evaluation of vegetation in a dryland using remote sensing is not completely accurate (White et al., 2000).

The above-mentioned concept has the consequences that the spectral properties of vegetation elements such as stems, leaves and fruits, can be considered the major determinant of canopy reflectance and influence the shape of the overall spectrum (Dorigo et al., 2007). Stems in the dryland ecosystem vegetation, play a small but significant role in determining canopy reflectance in woody plant canopies, especially those with leave area index (LAI) $<5.0$. However, this also depends on the location of woody material within the canopy (Asner, 1998). Standing litter significantly affects the reflectance characteristics of grassland canopies. Furthermore, small increases in the percentage of standing litter lead to unproportional changes in canopy reflectance (Fig. 1). Variation in litter optical properties plays a secondary role to structural attributes (e.g., leaf and litter area index) in determining canopy reflectance (Asner, 1998).

Regarding the leaves and their reflectance, we can find that they are spectrally dissimilar from their humid counterparts. They have adapted themselves to high temperature and high evaporation losses by adapting their surface in several ways, such as: reducing leaf size, avoiding leaves altogether and moving photosynthesis to the stalks and stem, shading the photosynthetic surface by a high density of reflective spines and leaf hairs or reducing losses due to evapotranspiration by a more waxy leaf cuticle (Ehleringer and Mooney, 1978). These differences affect the overall brightness of dryland vegetation (e.g. creosote - Larrea tridentata (DC.) Coville var. tridentata), the ratio of green vegetation to nonphotosynthetic vegetation within the canopy and perturbation to the shape of the spectrum at specific wavelengths (Fig. 2). 


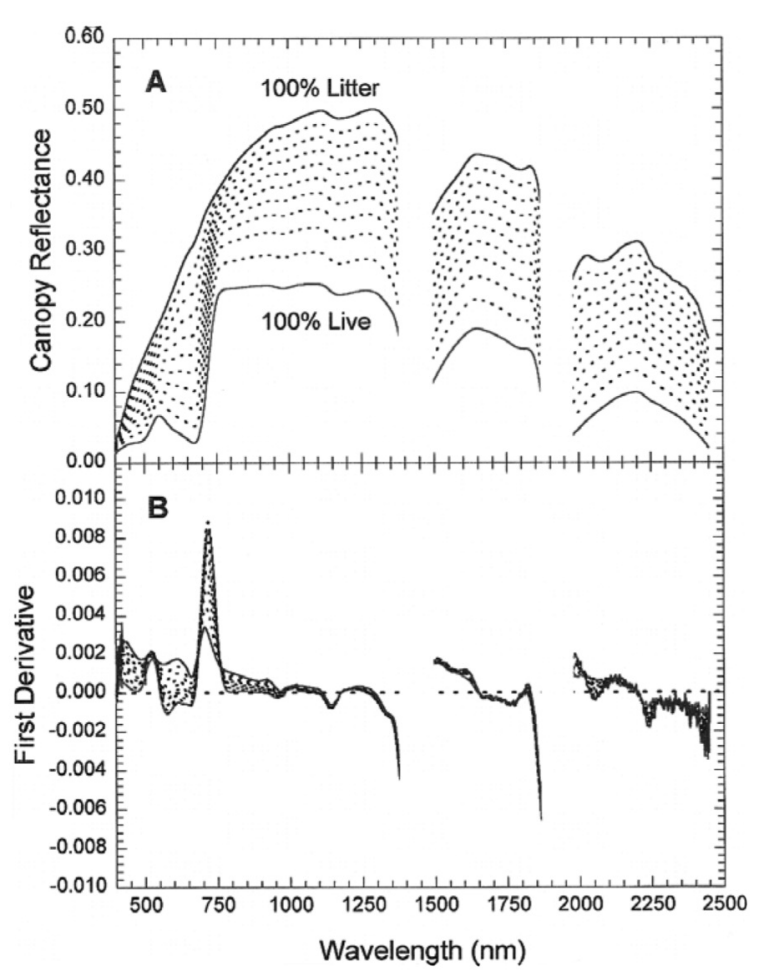

Figure 1. A) Effect of increasing the fraction of litter in a grassland canopy from $0 \%$ to $100 \%$ in simulated canopy reflectance. B) First derivative spectra coinciding with panel A (from Asner, 1998).

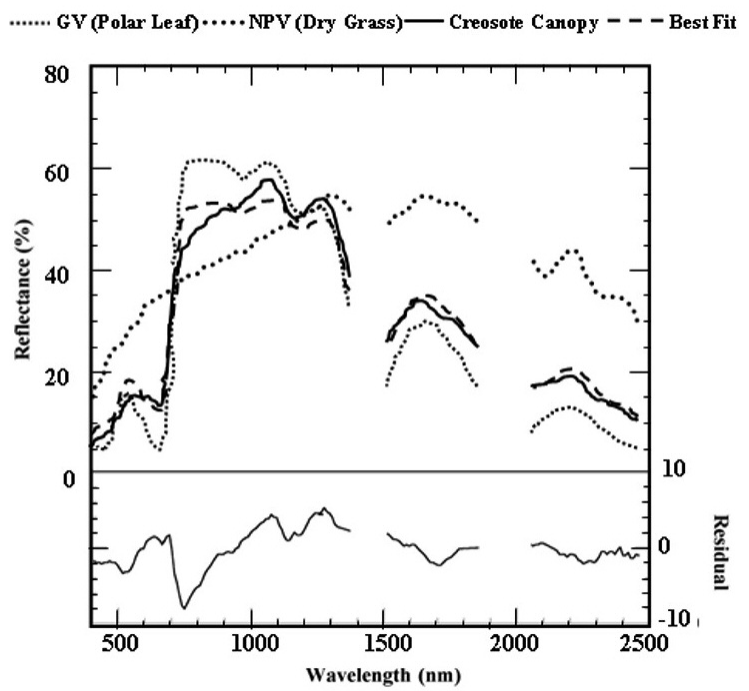

Figure 2. Comparison of green vegetation $(\mathrm{GV})$, nonphotosynthetic vegetation (NPV) and creosote canopy spectra. The best fit line is the optical linear least-squares mixture of GV and NPV to match the creosote spectrum. The residual of this mixture (residual = creosote canopy - best fit) is given in the bottom panel (from Okin and Robert, 2004).
Conditions are worsened by the fact that natural plants in arid and semiarid areas coordinate their phenological states with the availability of soil moisture to be able to complete rapidly their reproductive cycle. Persistent vegetation will come out of dormancy when water becomes available after the dry season or a period of drought, begin photosynthesis, and if time permits, produce flowers and fruits. When water again becomes scarce, vegetation will resume dormancy and in an extended period of drought some vegetation will shed their leaves. The total cycle in dryland regions takes place during a relatively short growing season (two to three months). Therefore, no single reflectance spectrum can represent the full spectral phenology of dryland plants, and spectra representing different phenological stages must be incorporated for quantitative information about vegetation change in both space and time (Okin and Robert, 2004).

The inability of the multispectral data to characterize the vegetation structure can be explained by the limited dimensionality as follows. Scientists have known since 1960 that a direct relationship exists between response in the near-infrared region and variation of vegetation biomass. On the other side, there is a inverse relationship between the vegetation biomass and visible region particularly the red region. To study the structure of the vegetation surface, a plot of near-infrared reflectance versus red reflectance (spectral feature space diagram) was used. At the end of the dry season, in semi-arid areas, bidirectional reflectance values, which are the values of a calibrated reflectance using the sun irradiance geometry function and sensor viewing geometry function, occupy a condensed envelope in spectral space. The pure bush, grass and soil samples lie along a brightness line, which means the red reflectance is equal to the near-infrared reflectance for pure bush, grass and soil samples (Fig. 3). This shows the inability of the multispectral data to characterize the vegetation structure. The limited dimensionality means that differences in reflectance between surface component (i.e. grass, bush and soil) are mainly restricted to changes in overall brightness (Trodd and Dougill, 1998).

The disability to provide information on vegetation structure from images acquired during the dry season has a number of important im- 


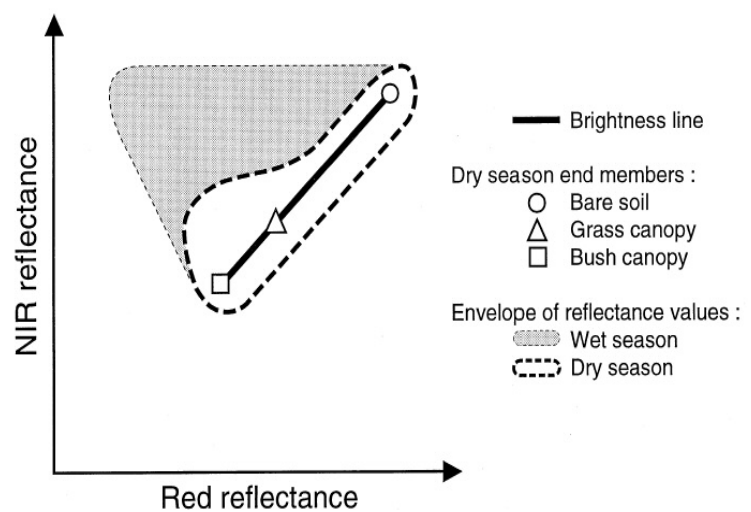

Figure 3. Schematic representation of landscape components in spectral feature space showing the distribution of all pixels in a scene in red and near-infrared multispectural space; the white area envelopes reflectance values in dry season and the white+gray area envelopes reflectance values in the wet season (from Trodd and Dougill, 1998).

plications regarding the role of satellite imagery in increasing our understanding of vegetation changes in semiarid areas. Particularly, it highlights on the need for long-term ground-based monitoring of changes in vegetation characteristics and data from new satellite sensors in order to help in developing different reflectance models and images analysis for the vegetation community in arid an semi-arid area (Ringrose et al., 1989).

\subsection{Anomalies in the arrangement of elements within the canopy}

Most types of dryland vegetation do not differ enough from one another to allow discernment of vegetation types by optical remote sensing (Okin et al., 2001). The within-species variation makes the problem worse as the spectral variability within a species can be greater than the variability between species (Franklin et al., 1993). In order to understand the above mentioned concept, the complication of vegetation community structure and inter-canopy shading are discussed.

Trodd and Dougill (1998) stated that as variations in the relative proportions of bush and grass cover in semiarid zones in Africa are likely to change the composite reflectance, it is apparent that the relationship between vegetation community structure and reflectance is ambiguous. In dryland vegetation community the reduction in reflectance can be due to an increase in vegetation cover and/or inter-canopy shading by bush canopies. Unfortunately, the two effects are not distinguishable and therefore, the relationship between vegetation community structure and reflectance cannot be inverted and used to estimate variations in vegetation structure (Trodd and Dougill, 1998).

Another important aspect in vegetation community structure in dryland is the possibility of the estimation of the percentage of nonphotosynthetic vegetation (NPV) using remote sensing. NPV whether in the form of dead shrubs or leafless drought-deciduous plants, plays an important role in the environment of dryland regions (Asner, 1998). It is useful in reducing wind and water erosion by contributing to the density of physical obstacles and total surface cover which protect the surface from erosion. Both wind and water erosion occur when surface cover is below approximately $15 \%$ (Wiggs et al., 1995). The difficulty is to determine the percentage of NPV and vegetation cover using remote sensing. Many common methods of estimating vegetation cover, such as vegetation indexes, are insensitive to the presence of NPV. They may not be useful to estimate the total cover in situations where NPV is a significant component of the surface cover (Asner, 2004).

\subsection{Optical interferences from the environment around the canopy (atmosphere and soil)}

The most important source of energy is the sun. Before the sun's energy reaches the Earth's surface, three fundamental interactions in the atmosphere are possible: absorption, transmission or scattering. The most efficient absorbers of solar radiation in the atmosphere are ozone, water and carbon dioxide. Atmospheric scattering occurs when the particles or gaseous molecules present in the atmosphere cause the electromagnetic waves to be redirected from their original path (Fig. 4).

Simple single scattering is represented as the product of the reflectance of an object times the intensity of the incoming radiation and is called linear mixing. For a given wavelength $(\lambda)$, we have:

$$
I_{r}(\lambda)=p(\lambda) I_{i}(\lambda)
$$

where $I_{r}(\lambda)$ is the intensity of the reflected light, $I_{i}(\lambda)$ is the intensity of the incident light, and $p(\lambda)$ is the reflectance spectrum of the object. 


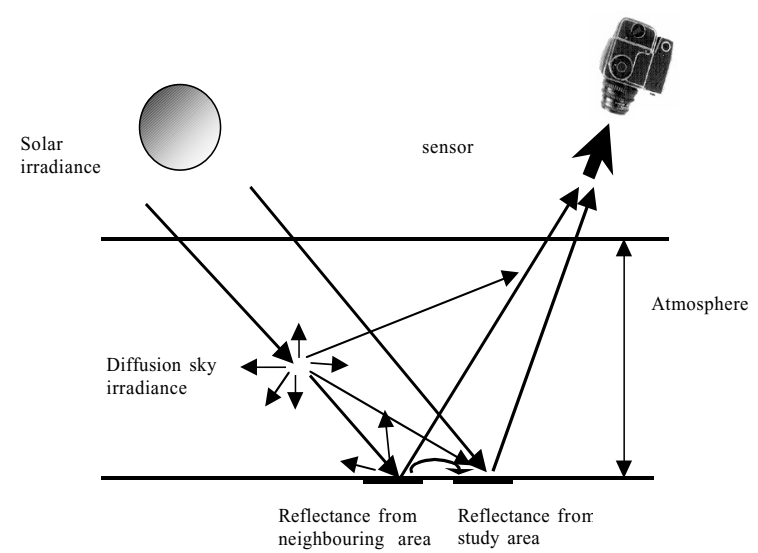

Figure 4. Radiance paths from the sun to the sensors: diffusion, scattering and multiscattering.

Multiple scattering or nonlinear mixing occurs when photons interact with more than one type of object on the Earth before returning to the sensor (Asner, 2004) and can be defined as follows:

$$
I_{r}(\lambda)=p_{1}(\lambda) p_{2}(\lambda) I_{i}(\lambda)
$$

where $p_{1}(\lambda)$ is the reflectance spectrum of the first object and $p_{2}(\lambda)$ is the reflectance spectrum of the second object.

In the arid and semiarid areas where bright soils often underlie vegetation with open canopies, the reflected light is highly affected by this type of multiple scattering. Therefore, correlations of reflected near-infrared radiation with LAI of open canopies of dryland shrubs are poor (Hurcom and Harrison, 1998). Also, in the case of leaf-to-leaf scattering and by referring to the definition of scattering (redirection of the reflectance not reduction), vegetation spectrum in the near-infrared is nonlinearly accentuated. In this case, there is more energy in the near-infrared, therefore, nonlinear mixing is likely to lead to an overestimation of green vegetation cover and an underestimation of shade (Roberts et al., 1993).

In soil, the spectral composition of reflected and emitted energy primarily depends on the biogeochemical (mineral and organic) constituents, optical geometric scattering (particle size, aspect, roughness) and surface moisture (Huete, 2004). Vegetation cover is well correlated with the presence or absence of soil organic matter. Soils in dryland ecosystem areas tend to be bright and mineralogically heteroge- neous because of their low organic matter, which tends to mask the spectral contribution of vegetation in individual pixels (Huete and Jackson, 1987).

\section{Techniques used in optical remote sensing in dryland ecosystems}

Since the launch of the first Earth Resource Technology Satellite (ERTS) on July 23, 1972, the analysis of data has advanced from simple visual observation to sophisticated interpretations based on first principles of spectroscopy and electromagnetic radiation (Ustin et al., 2004). Most remote sensing in arid regions has concentrated on optical remote sensing techniques which use data from sensors that collect radiation in the reflected solar spectrum. Two approaches are usually followed: a) calculation of vegetation indices; b) image classification.

\subsection{The calculation of vegetation indices}

Vegetation indices, reviewed by Jackson et al. (1983), Tueller and Oleson (1989) and others, are generally based on ratios of the radiance in the red and infrared spectral bands, chosen to maximize the reflectance contrasts between vegetation and other materials. The Normalized Difference Vegetation Index (NDVI) has been most commonly used to map spatial and temporal variation in vegetation (Tucker, 1979). The NDVI is a normalized ratio of NIR and red bands:

$$
N D V I=\frac{P_{N I R}-P_{r e d}}{P_{N I R}+P_{r e d}}
$$

where $P_{N I R-}$ and $P_{r e d}$ are the surface bidirectional reflectance factors.

NDVI is sensitive to pixel-level changes in greenness and fraction of photosynthetically active radiation absorbed, but it is not differentially sensitive to change in vegetation cover versus vegetation condition (i.e. the vigour, photosynthetic capacity or stress of vegetation canopy or cluster). This means that when an NDVI change occurs, it cannot be readily determined whether or not it was caused by altered vegetation cover or condition of cover. Moreover, NDVI has only limited success in providing accurate estimates of shrubland cover in arid regions and limited utility in the arid 
ecosystem. These facts are due to spectral variability of background materials such as soil and surface litter and the strength and variation of soil spectral albedo (i.e. a pixel may contain reflectance both from vegetation and soil), which causes nonlinearity in the relationship between NDVI and vegetation characteristics (Asner, 2004; Huete, 1988; Huete et al., 1992).

Huete (1988) and Huete et al. (1992) suggested the Soil Adjusted Vegetation Index (SAVI). They introduce a soil calibration factor, $L$, to the NDVI:

$$
S A V I=\frac{(1+L)\left(P_{N I R}-P_{r e d}\right)}{P_{N I R}+P_{r e d}+L}
$$

where $L$ is a soil calibration factor $(0-1)$. Compared to NDVI, SAVI allows to minimize soil background influences.

Regarding the relation between the vegetation indexes and NPV, the role of NPV on NDVI and SAVI was considered by Van Leeuwen and Huete (1996). The significant impact of NPV on these vegetation indexes was demonstrated, but it was so variable as to prevent the formulation of a single correction algorithm. Certainly, the variability of NDVI of the surface NPV is enormous, and NPV rarely has NDVI values close to zero (Fig. 5). Therefore, NDVI is difficult to be corrected for instability and ubiquity of NPV surface cover in dryland regions. Due to all these limitations, at the moment, operational guidelines to choose suitable vegetation indices are still lacking.

\subsection{Image classification}

Image classification usually relies on statistical methods including maximum-likelihood, clustering and discrimination analysis (Haralick and $\mathrm{Fu}, 1983)$ and methods based on principal components analysis (PCA) (Crist and Cicone, 1984). The aim of image classification is to link image spectra to dominant components in the image captured by the satellite (scene) or a characteristic mixture of components. It is assumed that spectrally similar data will thematically describe similar elements within a scene. It is also assumed that for each pixel there is dominant scene component, or at least a unique and identifiable suite of components that are present in distinctive proportions (Smith et al., 1990a).

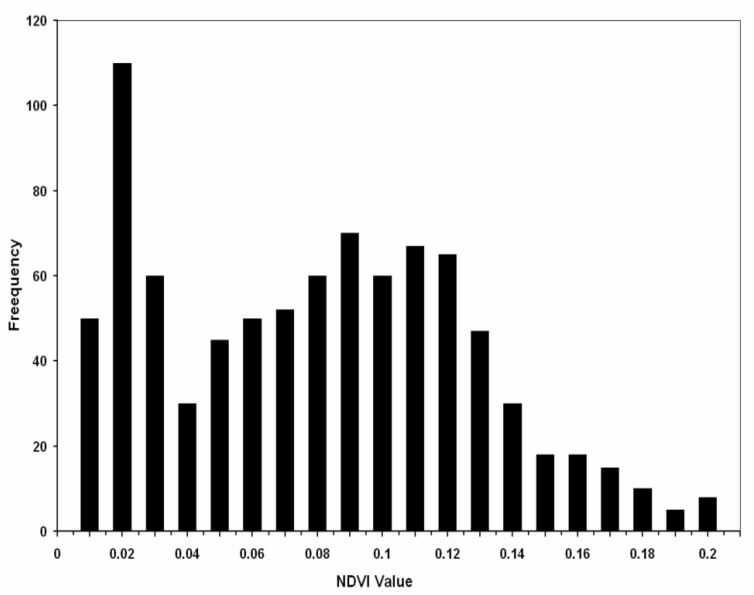

Figure 5. Histogram of NDVI values for nonphotosynthetic vegetation (NPV) collected across a broad range of arid and semiarid ecosystems $(\mathrm{n}=972)$ (from Asner, 2004).

PCA is used to identify a change in heterogeneity. To have an accurate measurement, when using this method, the pixel size must be smaller than the scale of variability of at least one of the principle landscape elements (grasslands or shrublands). If the pixel size is greater than the scale of variability, the differences between landscape elements will average out subpixels and spatial information is lost. If it is significantly smaller than the scale of heterogeneity, PCA can be used to examine the distribution of vegetation or soil in a landscape (Phinn et al., 1996).

Spectral mixture analysis (SMA) is a widely used method to unmix the soil-plant canopy measurements into the respective soil, vegetation and NPV single contributions (Smith et al., 1990a). The spectral response in remote sensing from open canopies is a function of the number and type of reflecting components, their optical properties and relative proportions (Adams et al., 1995).

SMA generally involves three steps: 1) assessment of dimensionality or number of unique reflecting materials in a landscape to get the end members; 2) identification of the physical nature of each of the landscape components or endmembers within a pixel; 3) determination of the amounts of each component in each pixel.

The basic SMA equation is:

$$
R_{P}(\lambda)=\sum_{i=1}^{n} f_{i} R_{i}(\lambda)+\varepsilon(\lambda)
$$


where $R_{P}(\lambda)$ is the apparent surface reflectance of a pixel in an image, $f_{i}$ are the weighting coefficients $\left(\sum_{i=1}^{n} f_{i}=1\right)$ interpreted as fractions

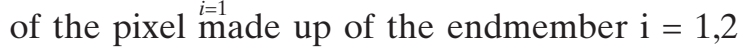
$\ldots \mathrm{n}, R_{i}(\lambda)$ are the reflectance spectra of spectral endmembers in an $n$-endmember model and $\varepsilon(\lambda)$ is the difference between the actual and modelled reflectance.

$f_{i}$ represents the best fit coefficient that minimizes RMS error (least-squares estimation) given by the following equation:

$$
R M S=\left[\frac{\sum_{j=1}^{m}\left(\varepsilon_{i}\right)}{m}\right]^{0.5}
$$

where $\varepsilon_{j}$ is the error term for each of the $m$ spectral bands considered.

SMA transforms radiation data into fractions of a few dominant endmembers spectra that correspond to scene components. Fraction images illustrate the mixing proportions of these endmembers spectra and therefore, via calibration to field data, the mixing proportions of the scene components can be depicted (Adams et al., 1986; Smith et al., 1985). SMA differs significantly from statistical classification in a number of ways, most significantly in the small number of endmembers compared to the potentially large number of thematic classes required to describe a scene with a statistical approach. Indeed, SMA separates the spectral contribution of these intrinsic scene components from shadow and other effects of illumination. This approach is particularly useful for measuring vegetation cover, especially in dryland regions where the proportions of vegetation and soil may vary significantly over a short distance (Smith et al., 1990a). Spectral mixture models are useful in a variety of applications, including biogeochemical studies, leaf water content, land degradation, land cover conversions, fuelwood assessment and soil and vegetation mapping (Huete, 2004).

Endmembers spectra can be measured in the laboratory, in the field, or from the image itself. Some SMA approaches use endmembers spectra derived from the image (e.g. Wessman et al., 1997; Elmore et al., 2000), whereas others em- ploy libraries of endmembers spectra, which are the empirical signature libraries (e.g. Smith et al., 1990a, b; Roberts et al., 1998). Although in drylands it is exceedingly difficult to locate image pixels containing $100 \%$ cover of each appropriate endmember, Bateson and Curtiss (1996) and Bateson et al. (2000) generated SMA model using PCA to explore image data in multiple dimensions. The technique allows the user to select endmember spectra based on inherent spectral variability of the image data without requiring homogeneous pixels of each endmember. Empirical signature libraries have been used widely, despite the recognition that libraries cannot easily capture the full range of endmember variability as found in nature (Asner, 2004). Indeed, it is unlikely and impractical that the spectral signature of the world's dominant vegetation could be collected given the tens of thousands of species that it would be necessary to identify, and when the range of possible phenological conditions is included, the method becomes impossible. However, the possibility that species and/or communities could be identified by a limited suite of biochemical and architectural characteristics permits new approaches to characterization of land cover properties (Ustin et al., 2004).

Another problem related to the application of SMA is nonlinear mixing, which can hinder the SMA applications (Roberts et al., 1993; Ray and Murray, 1996). However, the importance of the effect is not widely recognised since other studies (Villeneuve et al., 1998; Qin and Gerstl, 2000) showed that nonlinear mixing is a secondary feature. Moreover, Ustin et al. (1986) stated that the role of nonlinear mixing in determining the spectral reflectance variation of an ecosystem is wavelength dependent.

The performance of a spectral mixture model was compared against NDVI for mapping green canopy cover in semi-arid environment using thematic mapper (TM) data by Elmore et al. (2000) (Fig. 6). NDVI was loosely correlated with green cover but a marked increase in performance was obtained when utilizing the full potential of TM data via spectral mixture analysis (Elmore et al., 2000). Results showed that SMA was able to determine the 
SMA Vs. Field Data

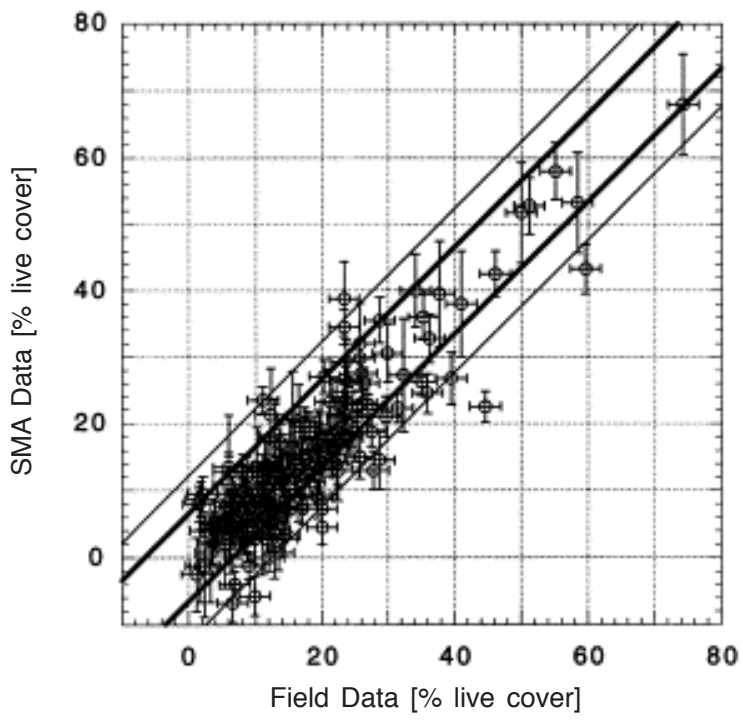

NDVI Vs. Field Data

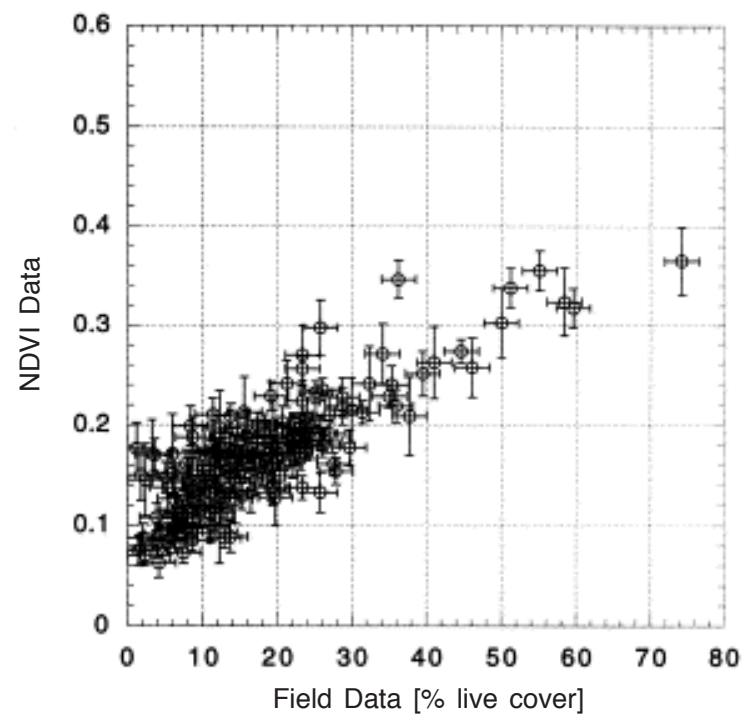

Figure 6. Comparison of subpixel green vegetation cover using Landsat TM imagery collected over a semiarid region: live cover measured in the field (x axis) plotted against (a) SMA results and (b) NDVI (from Elmore et al., 2000).

correct sense of change in percentage live cover and give precise estimates of the magnitude of that change.

\section{Conclusion}

Aerial and space remote sensing provide valuable tools for desertification studies, although they must be combined with ground-collected data. From the above review, it is clear that the variation of the spectral reflectance of vegetation in arid and semiarid areas changes with the vegetation structure and surrounding environment. To improve our skills in the interpretation of optical remote sensing data in dry ecosystem areas we should increase our understanding of components of these areas (vegetation structure, soil and atmosphere) and develop the techniques of data interpretation. Moreover, the empirical signature libraries should be developed according to regions and environments. The combination of remote sensing and ground-collected data can then provide the basis for the assessment of desertification.

\section{References}

Adams J.B., Sabol D.E., Kapos, V., Almeida Filho R., Roberts D.A., Smith M.O., Gillespie A.R. 1995. Clas- sification of multispectral images based on fractions of endmembers: Applications to land-cover change in the Brazilian Amazon. Remote Sensing of Environment, 52:137-154.

Adams J.B., Smith M.O., Johnson P.E. 1986. Spectral mixture modeling: a new analysis of rock and soil types at the Viking Lander I Site. Journal of Geophysics Researches, 91:8098-8112.

Asner G.P. 1998. Biophysical and biochemical sources of variability in canopy reflectance. Remote Sensing of Environment, 64:234-253.

Asner G.P. 2004. Biophysical remote sensing signatures of arid and semiarid ecosystem. In: Ustin S.L. (ed.): Remote Sensing for Natural Resources Management and Environmental Monitoring, 53-103. $3^{\text {rd }}$ edition, WILEY, New Jersey.

Bateson C.A., Asner G.P., Wessman C.A. 2000. Endmember bundles: A new approach to incorporating endmember variability in spectral mixture analysis. IEEE Transactions on Geoscience and Remote Sensing, 38:1083-1094.

Bateson C.A., Curtiss B. 1996. A method for manual endmember selection and spectral unmixing. Remote Sensing of Environment, 55:229-243.

Crist E.P., Cicone R.C. 1984. A physically-based transformation of Thematic Mapper data-the TM tasseled cap. IEEE Transactions on Geoscience and Remote Sensing, 22:256-263.

Dorigo W.A., Zurita-Milla R., Wit A.J.W. de, Brazile J., Singh R., Schaepman M.E. 2007. A review on reflective remote sensing and data assimilation techniques for enhanced agroecosystem modelling. Internation- 
al Journal of Applied Earth Observation and Geoinformation, 9:165-193.

Ehleringer J.R., Mooney H.A. 1978. Leaf hairs: effects on physiological activity and adaptive value to a desert shrub. Oecologia, 37:183-200.

Elmore A.J., Mustard J.F., Manning S.J., Lobell D.B. 2000. Quantifying vegetation change in semiarid environments. Remote Sensing of Environment, 73:87102.

Franklin J., Duncan J., Turner D.L. 1993. Reflectance of vegetation and soil in Chihuahuan desert plant communities from ground radiometry using SPOT wavebands. Remote Sensing of Environment, 46:291-304.

Haralick R.M., Fu K.S. 1983. Pattern recognition and classification. In: Cowell R.N. (ed.): Manual of Remote Sensing, 2:793-806. $2^{\text {nd }}$ edition, American Society of Photogramm, Fails Church, Virginia.

Hassan H., Luscombe W. 1990. Disaster information and technology transfer in developing countries. In: Kreimer A., Munasinghe M. (ed.): Proceedings of the Colloquium on the Environment and Natural Disaster Management, 27-28 June, World Bank, Washington, 141-144.

Huete A. 2004. Remote sensing of soil and soil processes. In: Ustin S.L. (ed.): Remote Sensing for Natural Resources Management and Environmental Monitoring, 3-51. $3^{\text {rd }}$ edition WILEY, New Jersey.

Huete A.R. 1988. A soil-adjusted vegetation index (SAVI). Remote Sensing of Environment, 25:295-309.

Huete A.R., Jackson R.D. 1987. Suitability of spectral indices for evaluating vegetation characteristics on arid rangelands. Remote Sensing of Environment, 23:213232.

Huete A.R., van Leeuwen W.J.D., Hua G., Qi J., Chehbouni A. 1992. Normalization of multidirectional red and NIR reflectances with the SAVI. Remote Sensing of Environment, 41:143-154.

Hurcom S.J., Harrison A.R. 1998. The NDVI and spectral decomposition for semiarid vegetation abundance estimation. International Journal of Remote Sensing, 19:3109-3125.

Jackson R.D., Slater P.N., Pinter P.J. 1983. Discrimination of growth and water stress in wheat by various vegetation indices through clear and turbid atmospheres. Remote Sensing of Environment, 13:187-208.

Jensen R.J. 2000. Remote Sensing of Environment. $3^{\text {rd }}$ edition, Pearson education, Delhi.

Lonergan S. 2005. The role of UNEP in desertification research and mitigation. Journal of Arid Environments, 63:533-534.

Okin G.S., Okin W.J., Murray B., Roberts D.A. 2001. Practical limits on hyperspectral vegetation discrimination in arid and semiarid environments. Remote Sensing of Environment, 77:212-225.

Okin G.S., Robert D.A. 2004. Remote sensing in arid regions: challenges and opportunities. In: Ustin S.L. (ed.): Remote Sensing for Natural Resources Man- agement and Environmental Monitoring, 111-147. $3^{\text {rd }}$ edition, WILEY, New Jersey.

Phinn S., Franklin J., Hope A., Stow D., Huenneke L. 1996. Biomass distribution mapping using airborne digital video imagery and spatial statistics in a semiarid environment. Journal of Environmental Management, 47:139-164.

Pickup G. 1995. A simple model for predicting herbage production from rainfall in rangelands and its calibration using remotely-sensed data. Journal of Arid Environments, 30:227-245.

Qin W., Gerstl S.A.W. 2000. 3-D scene modelling of semi-desert vegetation cover and its radiation regime. Remote Sensing of Environment, 74:145-162.

Ray T.W., Murray B.C. 1996. Nonlinear spectral mixing in desert vegetation. Remote Sensing of Environment, 55:59-64.

Ringrose S., Matheson W., Mogotsi B., Tempest F. 1989. The darkening effect in drought affected savanna woodland environments relative to soil reflectance in Landsat and SPOT wavebands. Remote Sensing of Environment, 30:1-19.

Roberts D.A., Smith M.O., Adams J.B. 1993. Green vegetation, non-photosynthetic vegetation, and soils in AVIRIS data. Remote Sensing of Environment, 44: 255-269.

Roberts D.A., Gardner M., Church R., Ustin S., Scheer G., Green R.O. 1998. Mapping chaparral in the Santa Monica Mountains using multiple endmember spectral mixture models. Remote Sensing of Environment, 65:267-279.

Smith M.O., Johnson P.E., Adams J.B. 1985. Quantitative determination of mineral types and abundances from reflectance spectra using principal components analysis, in: Ryder G., Schubert G. (ed.): Proceedings $15^{\text {th }}$ Lunar and Planetary Science Conference, 14-16 March 1984. American Geophysical Union, Houston, Texas, C797-C804.

Smith M.O., Ustin S.L., Adams J.B., Gillespie A.R. 1990a. Vegetation in deserts: I. A regional measure of abundance from multispectral images. Remote Sensing of Environment, 31:1-26.

Smith M.O., Ustin S.L., Adams J.B., Gillespie A.R. 1990b. Vegetation in deserts: II. Environmental influences on regional abundance. Remote Sensing of Environment, 31:27-52.

Trodd N.M., Dougill A.J. 1998. Monitoring vegetation dynamics in semi-arid African rangelands. Applied Geography, 18:4:315-330.

Tucker C.J. 1979. Red and photographic infrared linear combinations for monitoring vegetation. Remote Sensing of Environment, 8:127-150.

Tueller P.T., Oleson S.G. 1989. Diurnal radiance and shadow fluctuations in a cold desert shrub plant community. Remote Sensing Environment, 29:1-13.

Ustin S.L., Adams J.B., Elvidge C.D., Rejmanek M., Rock B.N., Smith M.O., Thomas R.W., Woodward 
R.A. 1986. Thematic mapper studies of semiarid shrub communities. BioScience, 36:446-452.

Ustin S.L., Zarco-Tejada P.J., Jacquemoud S., Asner G.P. 2004. Remote sensing of environment: state of science and new directions. In: Ustin S.L. (ed.): Remote Sensing for Natural Resources Management and Environmental Monitoring, 679-728. $3^{\text {rd }}$ edition, WILEY, New Jersey.

Van Leeuwen W.J.D., Huete A.R. 1996. Effects of standing litter on the biophysical interpretation of plant canopies with spectral indices. Remote Sensing of Environment, 55:123-134.

Villeneuve P.V., Gerstl S.A., Asner G.P. 1998. Estimating nonlinear mixing effects for arid vegetation scenes with MISR channels and observation directions. In: CH 36042 (ed.): Proceedings of the Inter- national Geoscience and Remote Sensing Symposium, 3-8 August 1997, Singapore, 3:31-35.

Wessman C.A., Bateson C.A., Benning T.L. 1997. Detecting fire and grazing patterns in tallgrass prairie using spectral mixture analysis. Ecological Applications, 7:493-512.

White M.A., Asner G.P., Nemani R.R., Privette J.L., Running S.W. 2000. Monitoring fractional cover and leaf area index in arid ecosystems: digital camera, radiation transmittance, and laser altimetry results. Remote Sensing of Environment, 74:45-57.

Wiggs G.F.S., Thomas D.S.G., Bullard J.E. 1995. Dune mobility and vegetation cover in the southwest Kalahari Deser. Earth Surface Processes and Landforms, 20:515-529. 